NASA-TM-111406

\title{
DEVELOPMENT OF A PRESSURE BOX TO EVALUATE REUSABLE- LAUNCH-VEHICLE CRYOGENIC-TANK PANELS
}

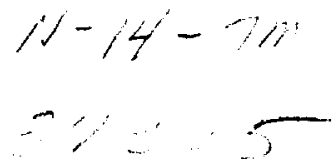

Damodar R. Ambur and Joseph Sikora

NASA Langley Research Center

Hampton, VA 23681-0001

James F. Maguire and Peter M. Winn

Applied Engineering Technologies, Ltd.

Westborough, MA

Presented at the AIAA/ASME/ASCE/AHS/ASC 37th Structures,

Structural Dynamics, and Materials Conference

Salt Lake City, Utah

April 15-17, 1996

AIAA Paper No. $96-1640$ 


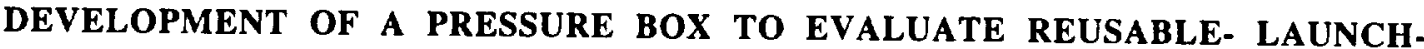 VEHICLE CRYOGENIC-TANK PANELS
}

\author{
Damodar R. Ambur* and Joseph Sikora** \\ NASA Langley Research Center \\ Hampton, VA 23681-0001 \\ James F. Maguire ${ }^{\dagger}$ and Peter M. Winn ${ }^{\dagger}$ \\ Applied Engineering Technologies, Ltd. \\ Westborough, MA
}

\begin{abstract}
A cryogenic pressure-box test machine has been designed and is being developed to test full-scale reusable-launch-vehicle cryogenic-tank panels. This machine is equipped with an internal pressurization system, a cryogenic cooling system, and a heating system to simulate the mechanical and thermal loading conditions that are representative of a reusable-launchvehicle mission profile. The cryogenic cooling system uses liquid helium and liquid nitrogen to simulate liquid hydrogen and liquid oxygen tank internal temperatures. A quartz lamp heating system is used for heating the external surface of the test panels to simulate cryogenic-tank external surface temperatures during re-entry of the launch vehicle. The pressurization system uses gaseous helium and is designed to be controlled independently of the cooling system. The tensile loads in the axial direction of the test panel are simulated by means of hydraulic actuators and a load control system. The hoop loads in the test panel are reacted by load-calibrated turnbuckles attached to the skin and frame elements of the test panel. The load distribution in the skin and frames can be adjusted to correspond to the tank structure by using these turnbuckles. The seal between the test panel and the cryogenic pressure box is made from a reinforced Teflon material which can withstand pressures greater than $52 \mathrm{psig}$ at cryogenic temperatures. Analytical results and tests on prototype test components indicate
\end{abstract}

\footnotetext{
* Senior Aerospace Engineer, Structural Mechanics Branch. Associate Fellow, ALAA.

**Electronics Engineer, Models, Instrumentation, and Systems Branch.

t Design and Development Engineer.
}

Copyright (c) 1996 by the American Institute of Aeronautics and Astronautics, Inc. No copyright asserted in the United States under Title 17, U.S. Code. that most of the cryogenic-tank loading conditions that occur in flight can be simulated in the cryogenic pressure-box test machine.

\section{Introduction}

Commercially competitive access to space using launch vehicles requires the development of advanced structures and thermal protection systems which are durable, highly operable, and require minimal maintenance. A joint NASA and aerospace industry program is in progress to develop a reusable launch vehicle (RLV) which will fly single-stage-toorbit missions. This vehicle design utilizes composite materials for the primary structure including the cryogenic tanks. One of the thermal-structural challenges for the RLV is the cryogenic tank system. The cryogenic tanks are insulated on the interior to contain liquid propellants at temperatures as low as $423^{\circ} \mathrm{F}$ and thermally protected on the exterior to limit the external temperature of the structure to approximately $250^{\circ} \mathrm{F}$. In addition to performing for these thermal conditions, the cryogenic tank structures should support the appropriate mechanical loading conditions and internal pressure corresponding to the mission conditions, and be reusable. There are four cryogenic-tank structural designs that are currently being developed by different aerospace companies with appropriate cryogenic and thermal protection systems. These full-scale cryogenic insulated curved panels need to be experimentally investigated with and without a thermal protection system to ensure that all aspects related to the structural response are evaluated and well understood. Pressurized structures of stiffened-skin construction exhibit local deformations, such as skinpillowing, which could affect the integrity of the internal and external insulation on the tank structure. Repeated application of loads through launch, ascent 
and reentry subject the cryogenic-tank structure to loading conditions that could result in cracking of the cryogenic insulation and microcracking of the tank structure, which would result in cryopumping. These structural responses and failure mechanisms for fullscale cryogenic-tank structures subjected to flight loading conditions have not been investigated.

A cryogenic pressure-box test machine has been designed and developed to test full-scale liquid hydrogen $\left(\mathrm{LH}_{2}\right)$ and liquid oxygen (LOX) tank structures with realistic flight loading conditions. The cryogenic pressure-box test machine is designed to generate a stress state in the test panel that is representative of the cryogenic-tank stress state for a corresponding loading condition. This test approach permits studying a panel to understand the cryogenictank response. The present paper describes features of the pressure-box test machine. Analytical results for the complete shell are presented and compared with results for the curved panel in the cryogenic pressurebox test machine to identify the region of the test panel where stress states are comparable to the complete shell. Details of the cryogenic process system will be presented to describe the unique features of this system, and a control sequence will be outlined for applying a given loading condition. Design details for the load-introduction structure will be discussed, and the seal configuration between the test panel and the cryogenic pressure box will be presented. Salient features of the heater system of the test machine will be discussed and its configuration will be presented.

\section{Loading Conditions and Test Panels}

Four tank structures are currently planned for testing in the test machine; three panels are for $\mathrm{LH}_{2}$ tanks and one is for a LOX tank. The hydrogen and oxygen tanks are pressurized to 35 psi and 44.6 psi, respectively. The loading conditions and their sequence of application during testing of a given panel are based on the loading conditions for the tank during different stages of flight in the mission profile. A typical mission profile for a reusable launch vehicle is presented in Figure 1. The test conditions for Panel 1, which is made of a graphite-epoxy material system and has a radius of $192.0 \mathrm{in}$., are presented in Table 1 . The panel will first be subjected to a 14-psig internalpressure condition with an internal temperature of $423^{\circ} \mathrm{F}$ to simulate the liquid hydrogen temperature. The panel exterior condition for this test case will be referred to herein as the "float" condition. The term "float" denotes an uncontrolled temperature condition and is attained by the panel as a function of time due to its thermal properties. The magnitude of the axial load in the panel is $1,344 \mathrm{lb} / \mathrm{in}$. to simulate the axial load condition corresponding to the internal pressure. The panel will subsequently be pressurized to 35 psig and the internal temperature is maintained at $-423^{\circ} \mathrm{F}$. This test condition corresponds to the launch-vehicle on-pad condition. The panel will then be subjected to an internal pressure of 35 psig and the external temperature of the thermal protection system (TPS) will be maintained at $1000^{\circ} \mathrm{F}$. This test condition simulates a reentry condition with some cryogen still in the tank. The TPS is designed such that the composite tank experiences only $250^{\circ} \mathrm{F}$ on the external surface and less than $250^{\circ} \mathrm{F}$ on the internal surface. The cryogenic pressure box was initially designed to satisfy these test conditions and was later modified to accommodate most of the test conditions listed in Tables 2-4 that correspond to test conditions for Panels 2-4. The second panel is for a liquid oxygen tank that has a radius of 156 in. and is made from an aluminum lithium material. The third and fourth panels are for liquid hydrogen tanks with radii of 130 in. and 266 in., respectively, and are made from composite materials. The loading conditions for Panels 2 and 3 are with and without the TPS. The soak condition for Panel 2 corresponds to the condition of the tank after the launch vehicle landing. The 5 psig pressure condition simulates the internal pressure condition for the tank with some unused cryogen remaining in the tank. The test conditions presented in Tables 1-4 suggest the nature of requirements for the test machine to accommodate panels of different radii and different combinations of loading conditions.

A schematic which identifies the panel construction and overall dimensions of Panel 1 is presented in Figure 2. The stringers and the frames are J-section stiffeners. The ten stringers are cocured with the skin while the frames rest on the stringers, and are attached to the panel skin and stringers with clips. The panel edges are reinforced to facilitate load introduction. The stringers are spaced 5.03-inches apart and the frame spacing is 31.5 inches. The frames are approximately 9-inches tall. This panel will be tested first in the cryogenic pressure box and discussions of structural analysis in the present paper will be limited to this panel.

\section{Simulation of Cryogenic-Tank Loading Conditions in the Test Machine}

The simulation of cryogenic-tank loading conditions in the cryogenic pressure- box test machine 
requires understanding the load distribution in the frame and skin elements of the tank structure. It is necessary to design appropriate load introduction structures that react loads in the structural elements while providing the correct boundary conditions. A general arrangement of the test panel assembly with axial and hoop load plates is shown in Figure 3(a). This test panel assembly will be mounted in the pressure-box test machine shown schematically in Figure 3(b). For this arrangement, the cryogenic pressure box located on the concave side of the panel pressurizes the panel and provides the cooling medium to lower the panel internal temperature to $-423^{\circ} \mathrm{F}$. The test panel is constrained in the hoop direction by turnbuckles and in the axial direction by hydraulic actuators. The turnbuckles react the hoop loads due to the internal pressurization of the panel while the hydraulic actuators apply axial tensile load to simulate the axial loads in the test panel. A room-temperature pressure box that utilizes a similar concept has been successfully developed and used earlier to evaluate subsonic transport aircraft fuselage crown panels (Ref. 1).

The hoop load distribution between the skin and frame elements is first determined by performing a finite element analysis of the shell structure. All analysis results presented in the present paper were obtained from the STAGS nonlinear finite element code (Ref. 2). A finite element model of the structure that represents the tank shell is presented in Figure 4. The model utilizes shell elements for the skin, frame, stringers and clips and has a total of 11,424 degrees of freedom. Since the panel is subjected to high internal pressure loading conditions, the influence of nonlinear effects on the panel response was investigated first. The hoop load results obtained from linear and nonlinear analyses are compared in Figure 5 for the panel subjected to 35 psig of internal pressure. Although the maximum out-of-plane displacements for the linear and nonlinear analyses are 0.8164 in. and 0.7768 in., respectively. The variation in the panel stress states for the two analyses is small. The stress gradients are better represented by the nonlinear analysis, especially at the frame attachment points, and hence the nonlinear analysis has been used throughout this section to generate panel response results. It was also determined from this analysis that the panel skin and frames support 80 percent and 20 percent of the total hoop load, respectively. The skin and frame turnbuckles that react the panel hoop loads in the cryogenic pressure box are designed with the appropriate stiffnesses to provide this load distribution between the skin and the frames. The load introduction plates in the axial and hoop directions and the straps or "finger" elements that attach the test panel to the loadintroduction plates are designed using standand engineering practices for structural design. A schematic of the test panel cross-sectional view through the axial load plate and the hydraulic actuator clevis (see Figure $3(\mathrm{~b})$ ) is shown in Figure 6. Schematic drawings of the hoop and axial loadintroduction plates are presented in Figure 7. The finger element fastening arrangement, the reinforced regions for the hoop load reacting turnbuckles, and the hydraulic actuator attachments in the axial direction are shown in this figure.

A finite element model of Panel 1 is shown in Figure 8. The model represents a quarter of the panel and includes the load-introduction plates which attach the test panel to the hydraulic actuator in the panel axial direction and to the load-introduction plate and frame turnbuckles in the hoop direction. This finite element model utilizes both shell, beam and rod elements and has 42,948 degrees of freedom. The hoop stress results for the test panel are compared with the shell analysis results In Figure 9(a) for an internal pressure of 35 psig. Boundary conditions imposed by the load-introduction structure influence the panel stress state in the region outboard of the frames. The stress state in the panel is relatively uniform from the region that is slightly outboard of the frame to the panel midsection and compares well with the shell stress state. The axial load distributions for the shell and the test panel for the same loading condition are compared in Figure 9(b). The panel also has a uniform axial stress state throughout with slightly higher stresses in the load-introduction region. These analysis results suggest that the shell stress state can be simulated in the test panel, and that the stress gradients along the length of the test panel attenuate within a short distance from the panel boundaries which provide a large enough test area for evaluation.

\section{Pressure Box and the Cryogenic Cooling System}

To satisfy the test conditions presented in Tables $1-4$, it is necessary that cryogens are used in the pressure box to simulate the panel internal temperature. Liquid helium has been chosen to be the medium to simulate the $-423^{\circ} \mathrm{F}$ tempearture condition to avoid the handling and safety considerations associated with liquid hydrogen. The other major design considerations were to separate the pressurizing system from the cooling system such that overall process control is simplified, and to use heat exchangers for cooling process efficiency. 
System layout

A schematic of the cryogenic pressure box system layout that satisfies the test conditions is shown in Figure 10(a). A sectional view of the cryogenic pressure box is shown in the figure with the test panel assembly mounted on it. The system is equipped with liquid helium and liquid nitrogen dewers to support the cooling system, and a gaseous helium tank is provided to pressurize the test panel. A separate boiler pod is constructed external to the cryogenic pressure box to house the heat exchangers and the liquid nitrogen boiler required to cool the test panel. A vacuum system is provided to compensate for any vacuum losses in the system. The connectivity between different components can also be seen in the figure. An enlarged cross-sectional view of the cryogenic pressure box is shown in Figure 10(b). The test panel is cooled by means of twelve heat exchangers or cooling plates located within the pressure box. These cooling plates have two sets of coils around them, one to circulate liquid nitrogen and the second to circulate liquid helium. In a typical test situation that requires cooling of the panel, the space below the test panel is filled with gaseous helium at the test pressure condition, and, depending on the temperature needed, either liquid helium or liquid nitrogen are circulated through the coils while fans recirculate the pressurized gas through the cooling plates. A C-seal shown in the figure is used to connect the test panel to the transition channel of the cryogenic pressure box so that the loss of internal pressure and heat are minimized while the test panel is permitted to float freely and deform radially due to the applied pressure.

\section{Cooling System Flow Diagram}

A flow diagram for the cooling system is presented in Figure 11(a). The pressure box is shown to the right of the figure and the boiler pod is shown to the left of the figure. The shaded areas represent the part of the system where vacuum is maintained. A system of valves is used to control the cryogen flow for cooling the test panel, and to vent and relieve the high-pressure gas in order to control the pressure in the box. A combination of vent valves and valves with burst diaphragms is used to protect the overall system from failure due to unanticipated events. Liquid helium and liquid nitrogen dewers are connected to the cooling plate coils and these coolants are circulated through the system by controlling valves V4 and V5. A cross-section of the fan heat exchanger is shown in
Figure 11(b). A gaseous helium tank with a supply pressure of approximately 2000 psi is used to provide a 200 psi pressure source for the pressure box to subject the test panel to an internal pressure of up to $52 \mathrm{psig}$. Heat exchangers $\mathrm{HX} 1, \mathrm{HX} 2$ and $\mathrm{HXN}$ are cross-flow heat exchangers that help reclaim useful energy from the exhausting gases. In a typical test for Panel 1, the panel needs to be internally pressurized to 35 psig while cooled to $-423^{\circ} \mathrm{F}$, and gaseous helium is first circulated through the pressure box to purge its volume of air. Next, gaseous helium is pumped and circulated in the pressure box by activating the fans while liquid nitrogen is circulated through the cooling plate coils by opening valves V5 and V6. This part of the cooling procedure is intended to minimize the consumption of the more expensive liquid helium when cooling the test panel to the required test temperature. After the test panel is cooled to $-320^{\circ} \mathrm{F}$ and the internal pressure reaches a value of approximately $25 \mathrm{psig}$, the supply of liquid nitrogen is discontinued and liquid helium is circulated through the cooling plate coils by opening valve $\mathrm{V} 4$ to reduce the temperature of the panel to $-423^{\circ} \mathrm{F}$. A total of 12 fans, which are located beneath the cooling plates, are used to circulate the pressurized helium gas. The fan motors are physically located outside of the cooled region of the pressure box to reduce the thermal load on the cooling system. For purposes of designing the cooling system, a total heat load of $0.95 \mathrm{Btu} / \mathrm{sec}$ was assumed for the test panel, the load-introduction structure, the pressure box, and the hoop load reacting rods.

\section{Structural Analysis of the Pressure Box}

A finite element analysis of the pressure box was conducted to ensure that the stress levels in the box are within the allowable strength values for the material, and that the warm and cold surfaces on either side of the vacuum jacketed portion of the box do not come into contact with one another due to the pressure loading on these surfaces. A quarter model of the pressure box has been developed using the Images 3D modeling code (Ref. 3) and is shown in Figure 12(a). The material for the pressure box is stainless steel 340 with a modulus of elasticity of $28.0 \mathrm{Msi}$ and a Poisson's ratio of 0.3 . The model consists of 565 plate elements and has approximately 12,500 degrees of freedom. The outer surfaces of the vacuum jacket were subjected to a pressure load of $14.7 \mathrm{psi}$, and the surfaces that will experience the $54 \mathrm{psig}$ maximum test pressure condition were subjected to $68.7 \mathrm{psi}$ in the analysis. The dead weight of the box is also included 
in the stress analysis. The deflection contours of the pressure-box walls are presented in Figure 12(b). The maximum deflection for the inner vessel is 0.16 in. which is negligible compared the 3.0 in. space between the inner and outer walls. The stress contours of the inner and outer walls of the pressure box corresponding to the above pressure load condition are presented in Figures 13(a) and 13(b). The maximum inplane stress value of 23,200 psi occurs in the vertical side plate of the pressure box that rests on the support structure. This stress is lower than the allowable stress of 28,200 psi for this material. Welding of the pressure box will be done in the low stress areas and 100 percent weld inspection will be performed to assure the structural strength.

Test Panel and Load-Introduction Structure Boundary Conditions

A thermal analysis of the test panel and loadintroduction structure assembly was performed to determine the thermal boundary conditions necessary for the load introduction structure so that the total heat load on the cooling system from all sources related to the test article is less than the assumed value of 0.57 Btu/sec. A finite element model of the test panel, the load-introduction structure and the pressure box was generated using Images 3D modeling code and analysis was performed to determine the heat loads and thermal gradients developed by cooling the test panel to $423^{\circ} \mathrm{F}$. The model has 1,796 plate elements, 360 solid elements and approximately 32,000 degrees of freedom. Solid elements are used to model the foam insulation inside the pressure box. The analysis assumes $-440^{\circ} \mathrm{F}$ for the inner gas temperature and $80^{\circ} \mathrm{F}$ for the ambient temperature. Three different load cases are analyzed to determine the actual thermal condition to be imposed on the load-introduction structure. These load cases are: (1) the load-introduction structure is not insulated; (2) the load-introduction structure is very well insulated and the actuator and turnbuckle attachment points at the end of the load plates are maintained at a constant temperature of $80^{\circ} \mathrm{F}$; and (3) the load plates are moderately insulated while temperatures at the actuator and the turnbuckle attachment points are allowed to vary.

For the analysis of the first load case, a $0.88 \mathrm{Btu} / \mathrm{hr} . \mathrm{ft}^{2}{ }^{\circ}{ }^{\circ} \mathrm{F}$ heat transfer coefficient was assumed for the upper surface of the load-introduction plates and the test panel, and a $0.18 \mathrm{Btu} / \mathrm{hr} . \mathrm{ft}^{2}{ }^{\circ} \mathrm{F}$ heat transfer coefficient was assumed for the lower plates. The finger elements are assumed to be insulated. A heat transfer coefficient of $4.8 \mathrm{Btu} / \mathrm{hr} . \mathrm{ft}^{2}{ }^{\circ}{ }^{\circ} \mathrm{F}$ was calculated for the internal fans. The analysis results for this case are presented in Figure 14(a). For this case, the inside surface temperature of the test panel is at $-423^{\circ} \mathrm{F}$ and the edges of the load-introduction plates are essentially at room temperature. The lateral heat load through the fingers for this condition is estimated to be 0.85 Btu/sec which exceeds the assumed value. The analysis of the second load case was conducted assuming that the load-introduction plates are very well insulated and the ends of the plates are exposed to $80^{\circ} \mathrm{F}$ temperature at the hydraulic actuator and turnbuckle attachment points. For this case, the load-introduction plates reach temperatures of less than $-190^{\circ} \mathrm{F}$ and the heat load through the finger elements reduces to $0.19 \mathrm{Btu} / \mathrm{sec}$. A temperature contour plot of the test panel and the loadintroduction structure for the second load case is presented in Figure 14(b). The inner surface of the test panel can be maintained at a $-427^{\circ} \mathrm{F}$ temperature for this load case. Accommodating the estimated thermal loading values for the load cases 1 and 2 will need a significant increase in liquid helium consumption. The analysis of the third load case assumes a moderate insulation on the load-introduction plates (assumed to have a heat transfer coefficient of $0.09 \mathrm{Btu} / \mathrm{hr} . \mathrm{ft}^{2}{ }^{\circ} \mathrm{F}$ ). The analysis results for this case are presented in Figure 14(c). The load introduction structure for this case is cold at $-315^{\circ} \mathrm{F}$ and the heat load through the finger elements is approximately $0.05 \mathrm{Btu} / \mathrm{sec}$. The results of this analysis suggests that the load plates need to be cooled to limit the thermal loads into the cryogenic box through the load-introduction structure. Cooling the load introduction plates will be done by means of liquid nitrogen trace cooling. From this analysis, it was also determined that the thermal loads from the test panel, the pressure-box assembly, and the turnbuckles will be $0.52 \mathrm{Btu} / \mathrm{sec}, 0.19 \mathrm{Btu} / \mathrm{sec}$, and $0.095 \mathrm{Btu} / \mathrm{sec}$, respectively.

\section{Seal Arrangement}

As mentioned previously in the present paper, the test panel essentially acts as a cover plate for the cryogenic pressure box and is connected to the box by a C-shaped seal. Also, the load-introduction structure and the finger elements need to be insulated from within and sealed to minimize liquid helium consumption. Two seals are used for this purpose as shown in Figure 15. The finger seal protects and seals the load-introduction structure and the finger elements, while the $\mathrm{C}$-seal attaches the test panel to the pressurebox transition channel to minimize the cryogen loss. The finger seal is made of layers of Teflon material which will be bonded to the test panel using a suitable 
adhesive. The $\mathrm{C}$-seal will be made of Teflon-reinforced Teflon sheets to support the 52 psig internal pressure condition at cryogenic temperatures.

\section{Heater Systems}

Two heater systems are needed to generate the test conditions outlined in Tables 1-4. One heater system will be used to heat the TPS covered external surface of the test panel to a maximum of $1000^{\circ} \mathrm{F}$ and the second heater system will be used inside the cryogenic pressure box to simulate the soak temperature condition of $250^{\circ} \mathrm{F}$ on the interior surface of the cryogenic-insulated test panel. The interior heater may also be used to heat the pressure box so that elevated- temperature test conditions can be achieved more readily after a cold test condition.

An array of quartz lamps will be used to heat the external surface of the panel and a heater coil system will be used inside the cryogenic box. Since the panels have different curvatures, it was decided to develop a flat heater array with different lamp zones to accommodate increasing heat flux as the space between the curved plate and the flat heater increases away from the center of the panel. Electrical wiring for the heater will provide for a total of ten heating zones. The quartz lamp spacing was influenced by the need to compensate for the heat flux variations for the different panel curvatures. The electrical power needed to perform a $1000^{\circ} \mathrm{F}$ test is estimated to be $365 \mathrm{Btu} / \mathrm{sec}$. The heater array will have a 8-ft.-square planform with approximately five quartz lamps per square foot, which amounts to a total of 268 lamps. The lamps will be mounted on a 0.032 -in.-thick aluminum sheet with specular finish and provisions will be made for the heater support structure to allow for the thermal expansion of this aluminum reflector. The backside of the reflector is roughened and painted with a high emissivity paint. A photograph of the heater is presented in Figure 16. The heater surface will be positioned at a distance of six inches away from the test panel surface to minimize individual lamp effects on the test surface. A mock-up heater array was fabricated and tested to ensure that the reflector performs adequately at heat fluxes needed to produce $1000^{\circ} \mathrm{F}$ on the TPS- covered test-specimen surface.

\section{Concluding Remarks}

Design of a cryogenic pressure-box test machine has been completed. This test machine will provide test conditions needed to evaluate full-scale cryogenic-tank panels in the laboratory. The cooling process system has been designed to provide flexibility in the cooling conditions at a minimum cost. The total heat load on the cooling system is estimated to be approximately $0.95 \mathrm{Btu} / \mathrm{sec}$. This estimate is based on liquid-nitrogen trace cooling of the load-introduction structure. A dual seal arrangement has been used for the thermal insulation and for a pressure containing medium. A quartz-lamp heater system has been designed and developed to accommodate test panels of different radii of curvature. The seals and the heater system have been validated through prototype tests.

\section{Acknowledgments}

The authors would like to acknowledge Dr. Rao V. Ganni of the Central Electron Beam Acceleration Facility (CEBAF), Newport News, VA for his valuable suggestions in developing the cooling process system.

\section{References}

1. Rouse, M., and Ambur, D. R., "Fuselage Response Simulation of Stiffened Panels Using a Pressure-Box Test Machine," AIAA Paper No. 951362, 36th AIAA/ASME/ASCE/AHS/ASC Structures, Structural Dynamics, and Materials Conference, New Orleans, LA, April 1995.

2. Brogan, F. A., Rankin, C. C., and Cabiness, $H$. D., "STAGS User Manual," Lockheed Palo Alto Research Laboratory, Report LMSC P032594, 1994.

3. Anon., "Images 3D: Users Manual," Celestial Software, Inc., Berkley, CA, 1990. 
Table 1. Panel 1 test conditions ( Panel radius $=192$ in.)

\begin{tabular}{llllll}
\hline \hline Test condition & $\begin{array}{l}\text { Internal } \\
\text { pressure, psi }\end{array}$ & $\begin{array}{l}\text { Temperature. }{ }^{\circ} \mathrm{F} \\
\text { Internal External }\end{array}$ & $\begin{array}{l}\text { Loads, lb/in. } \\
\text { Hoop Axial }\end{array}$ \\
& & & & & \\
\hline With TPS: & 14.0 & -423 & Float & 2,688 & 1,344 \\
First cycle (40\% full load) & 35.0 & -423 & Float & $6,720 \quad 3,360$ \\
Subsequent cycles & 35.0 & $<250$ & Float & $6,270 \quad 3,360$ \\
\hline \hline
\end{tabular}

Table 2. Panel 2 test conditions (Panel radius $=156$ in.)

\begin{tabular}{|c|c|c|c|c|c|}
\hline \multirow[t]{2}{*}{ Test condition } & \multirow{2}{*}{$\begin{array}{l}\text { Internal } \\
\text { pressure, psi }\end{array}$} & \multirow{2}{*}{\multicolumn{2}{|c|}{$\frac{\text { Temperature. }{ }^{\circ} \mathrm{F}}{\text { Internal External }}$}} & \multicolumn{2}{|c|}{ Loads. Ib/in. } \\
\hline & & & & Hoop & Axial \\
\hline \multicolumn{6}{|l|}{ 0.5-in-thick: } \\
\hline Vehicle on launch pad & 44.6 & -320 & Float & 6,960 & 3,480 \\
\hline Ascent & 44.6 & -320 & $<350$ & 6,960 & 3,480 \\
\hline \multicolumn{6}{|c|}{$\begin{array}{l}\text { With cryogenic insulation } \\
\text { and TPS: }\end{array}$} \\
\hline Vehicle on launch pad & 44.6 & -320 & Float & 6,960 & 3,480 \\
\hline Ascent & 44.6 & -320 & $<600$ & 6,960 & 3,480 \\
\hline Reentry & 5.0 & 50 & $<1000$ & 780 & 390 \\
\hline Soak & 5.0 & $<250$ & Float & 780 & 390 \\
\hline
\end{tabular}

Table 3. Panel 3 test conditions (Panel radius $=130$ in.)

\begin{tabular}{|c|c|c|c|c|c|}
\hline \multirow[t]{2}{*}{ Test condition } & \multirow{2}{*}{$\begin{array}{l}\text { Internal } \\
\text { pressure, psi }\end{array}$} & \multirow{2}{*}{\multicolumn{2}{|c|}{$\begin{array}{l}\text { Temperature, }{ }^{\circ} \mathrm{F} \\
\text { Internal External }\end{array}$}} & \multicolumn{2}{|c|}{ Loads. lb/in. } \\
\hline & & & & Hoop & Axial \\
\hline \multicolumn{6}{|l|}{ 0.5-in-thick: } \\
\hline Vehicle on launch pad & 34.0 & -423 & Float & 4,420 & 3,084 \\
\hline Ascent & 34.0 & -423 & $<150$ & 4,420 & 3,084 \\
\hline \multicolumn{5}{|l|}{ With cryogenic insulation } & \\
\hline Vehicle on launch pad & 34.0 & -423 & Float & 4,420 & 3,480 \\
\hline Ascent & 34.0 & -423 & $<490$ & 4,420 & 3,480 \\
\hline Reentry & 5.0 & 50 & $<1000$ & 650 & 454 \\
\hline Soak & 5.0 & $<250$ & Float & 650 & 454 \\
\hline
\end{tabular}

Table 4. Panel 4 test conditions (Panel radius $=266$ in.)

\begin{tabular}{|c|c|c|c|c|c|}
\hline \multirow[t]{2}{*}{ Test condition } & \multirow{2}{*}{$\begin{array}{l}\text { Internal } \\
\text { pressure, psi }\end{array}$} & \multirow{2}{*}{\multicolumn{2}{|c|}{$\begin{array}{l}\text { Temperature. }{ }^{\circ} \mathrm{F} \\
\text { Internal External }\end{array}$}} & \multicolumn{2}{|c|}{ Loads lb/in. } \\
\hline & & & & Hoop & Axial \\
\hline \multicolumn{6}{|l|}{ No TPS: } \\
\hline Ascent & 32.0 & -423 & -275 & 6,400 & 3,200 \\
\hline On-orbit & 22.1 & 150 & 150 & 4,426 & 2,930 \\
\hline Reentry & 22.1 & $<370$ & 400 & 4,426 & 2,930 \\
\hline
\end{tabular}




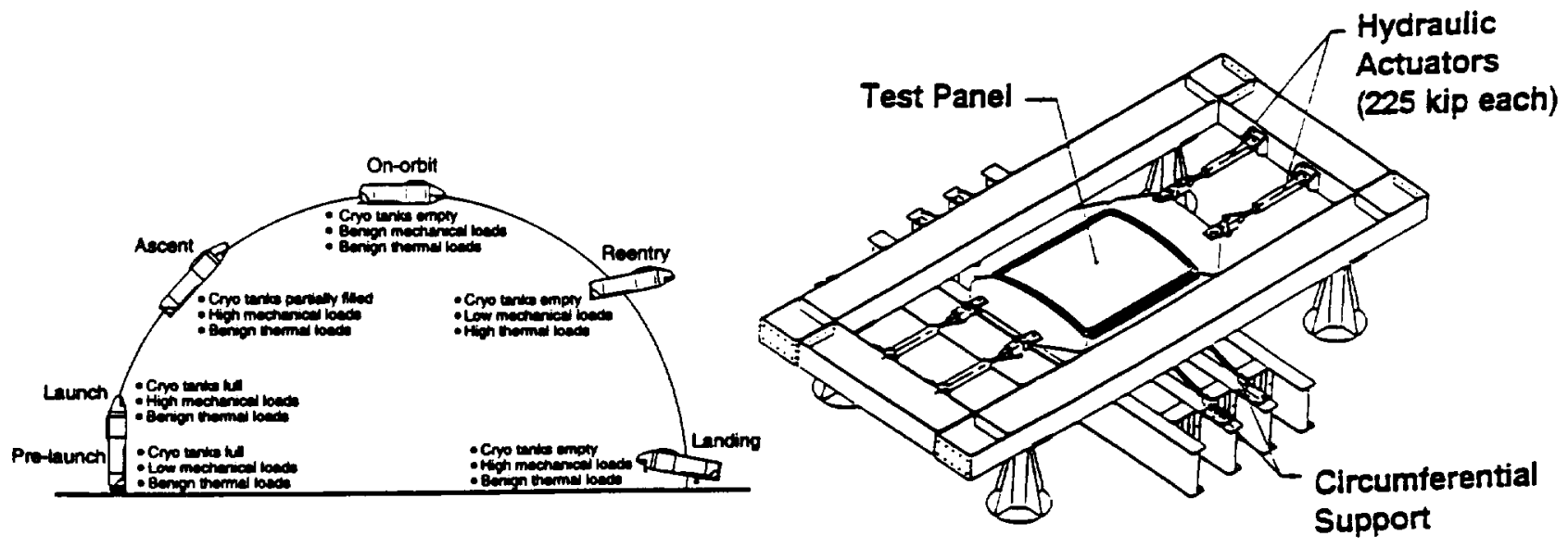

Figure 1. A reusable launch vehicle flight profile and environment during a typical mission.

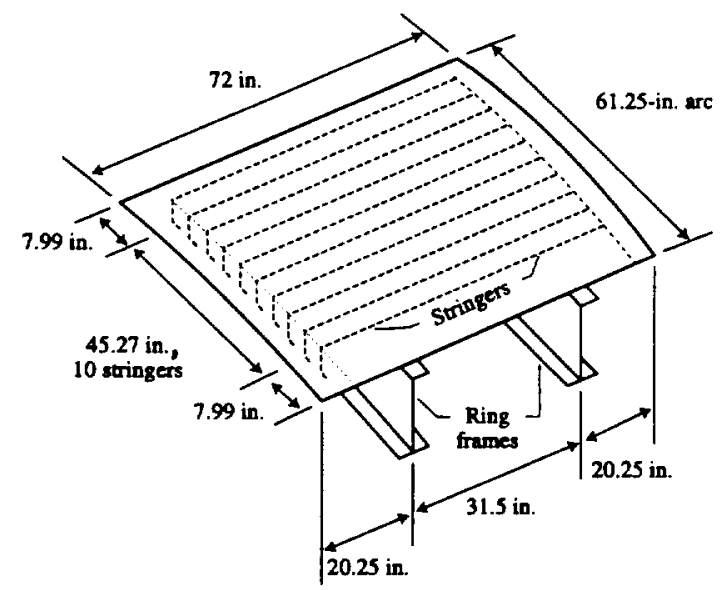

Figure 2. Configuration and structural details for Panel 1.

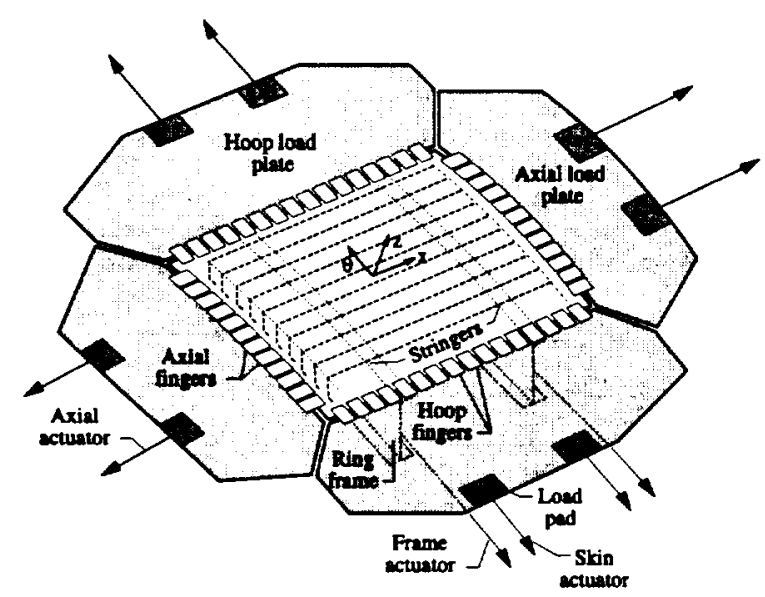

a. Schematic of test panel assembly with load introduction structure.

Figure 3. Continued.

b. Schematic of the pressure-box test machine.

Figure 3. Pressure-box test machine concept.

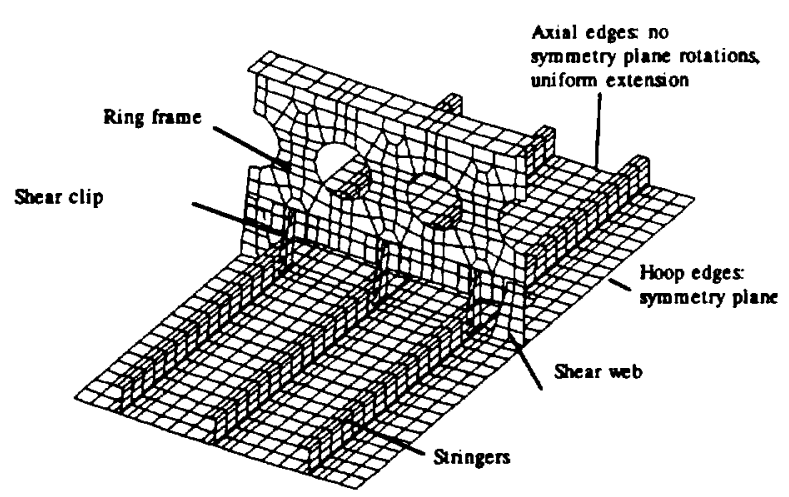

Figure 4. Finite element model of the Panel 1 shell structure.

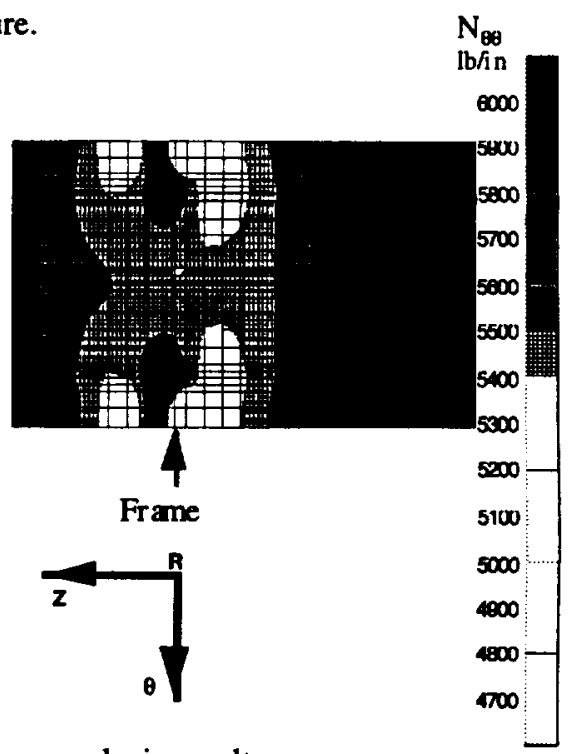

a. Linear analysis results.

Figure 5. Comparison of hoop load distributions from the geometrically linear and nonlinear analyses for the shell.

American Institute of Aeronautics and Astronautics 


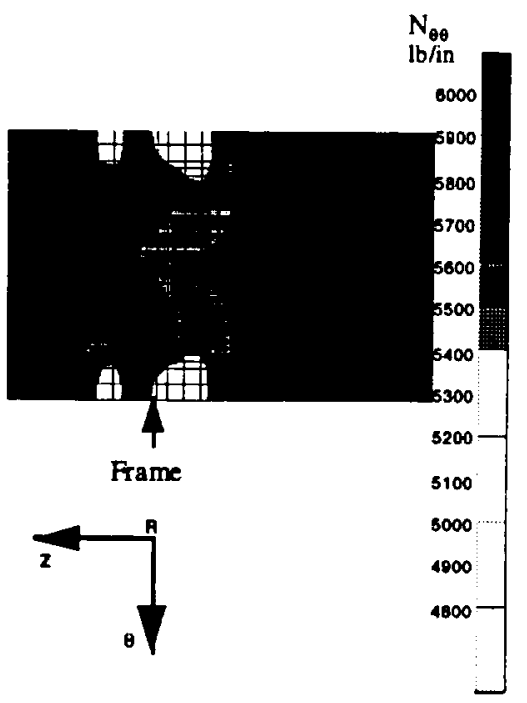

b. Nonlinear analysis results.

Figure 5. Concluded.

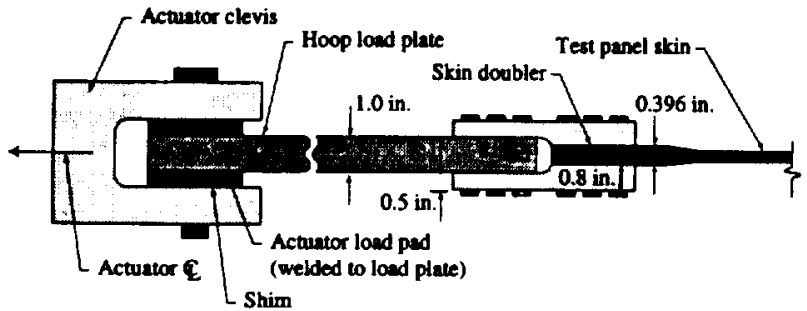

Figure 6. Cross-sectional view of the test panel assembly with hydraulic actuator clevis.

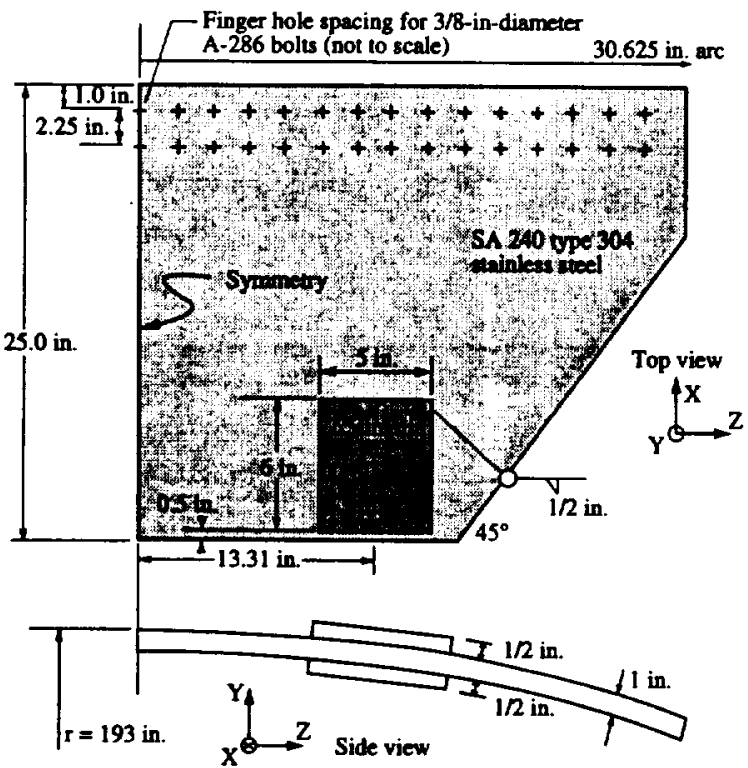

a. Axial load plate.

Figure 7. Continued.

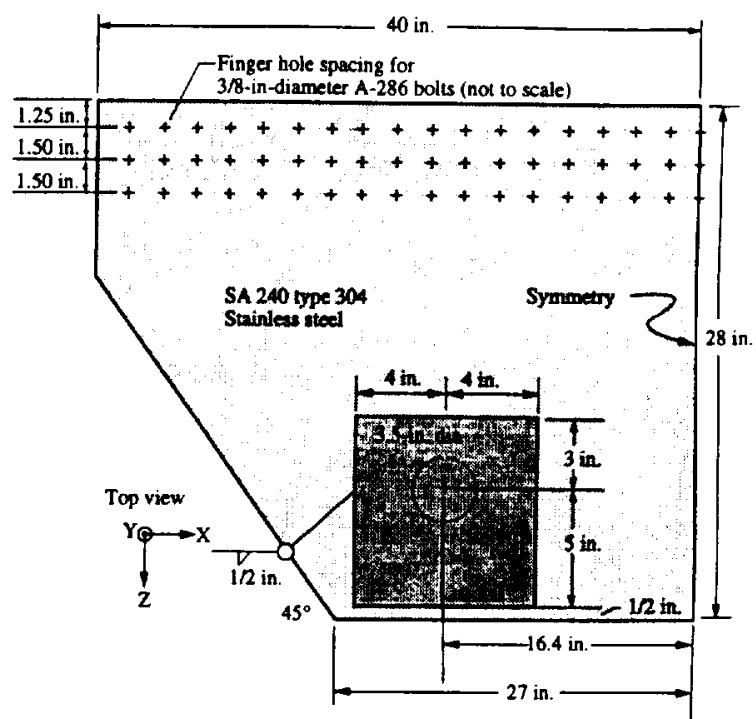

b. Hoop load plate.

Figure 7. Load introduction plate configurations.

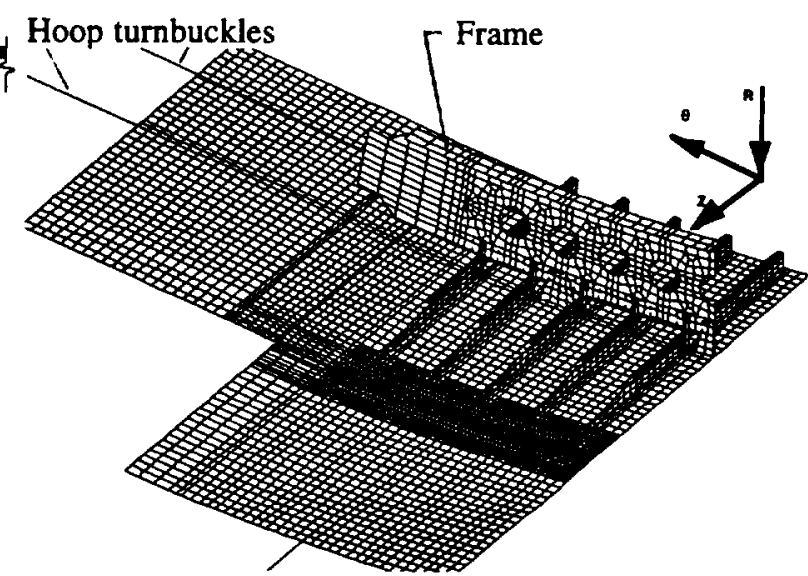

Axial actuator

Stringers

Figure 8. Finite element model of Panel 1 assembled in the pressure-box test machine. 

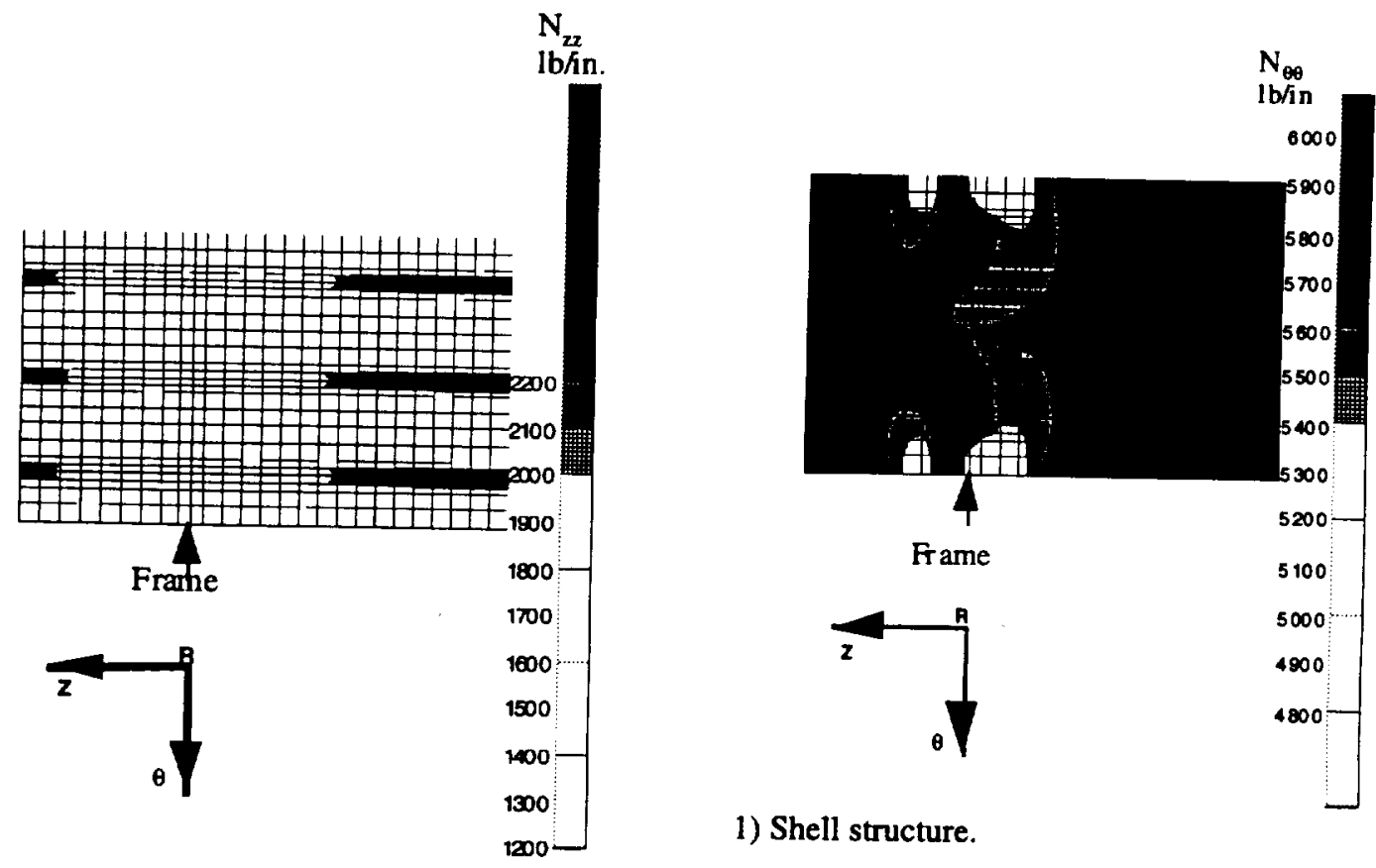

1) Shell structure.

1) Shell structure.
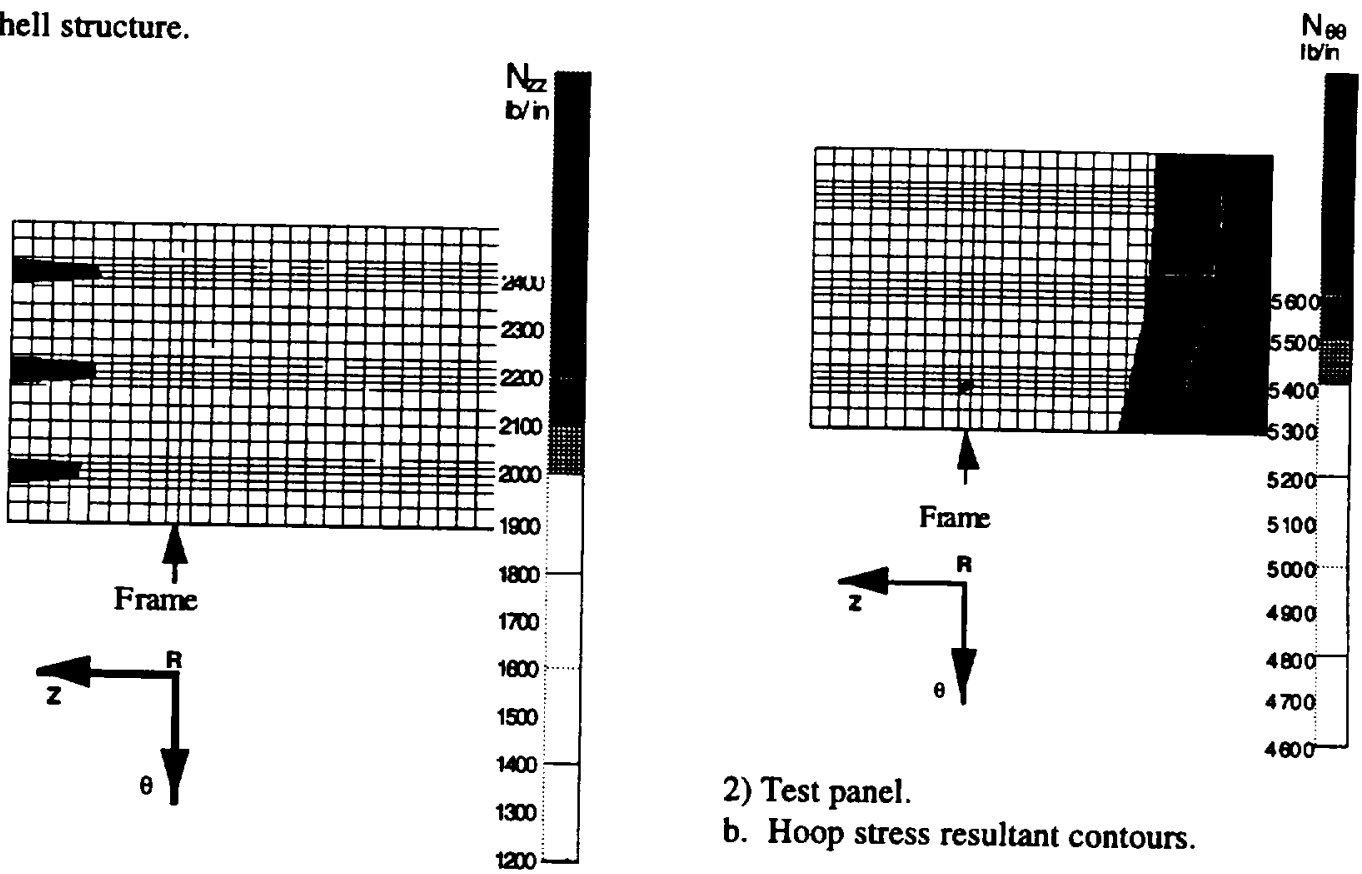

2) Test panel.

b. Hoop stress resultant contours.

2) Test panel.

Figure 9. Comparison of Panel 1 and shell stress resultants for an internal pressure condition of 35 psig.

Figure 9. Continued. 


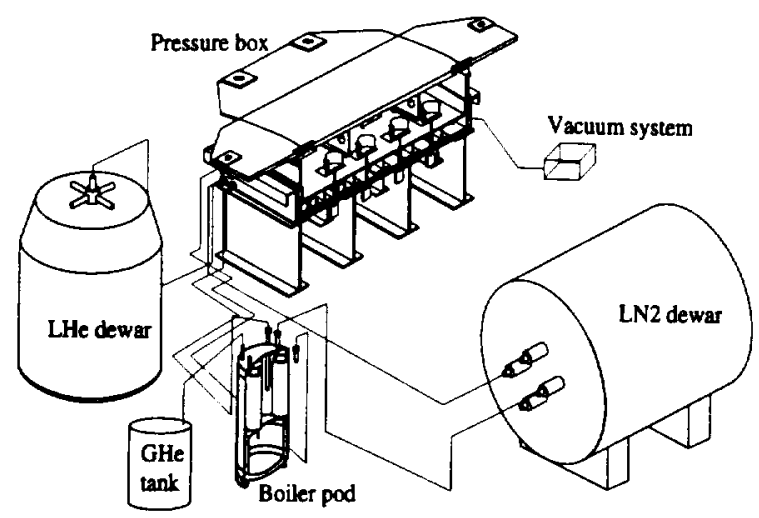

a. Schematic of the cryogenic pressure-box system layout.

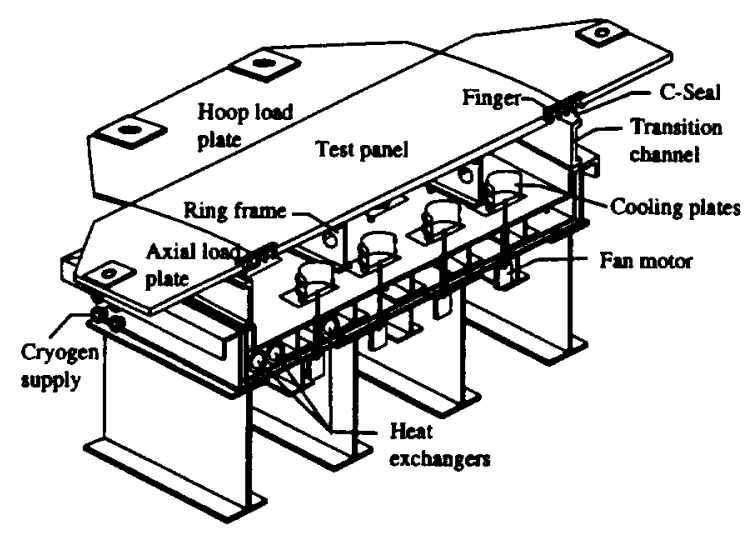

b. Schematic of the pressure box with test panel assembly.

Figure 10. Cryogenic pressure-box system.

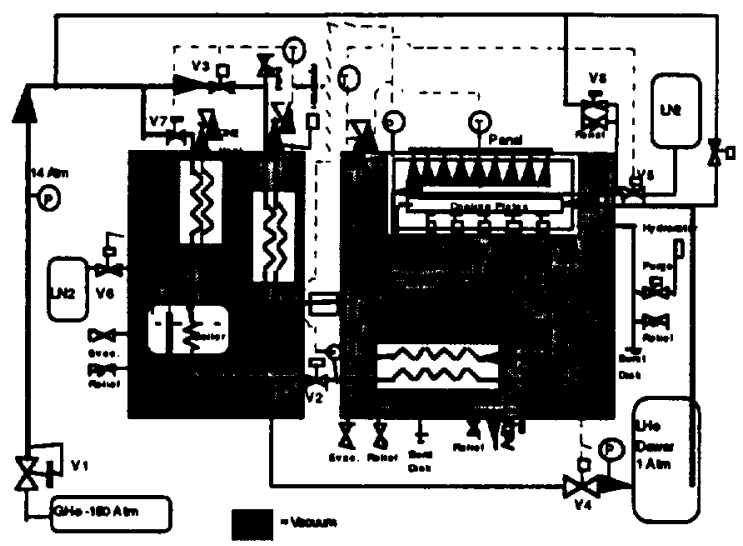

a. Flow diagram for the cooling system.

Figure 11. Continued.

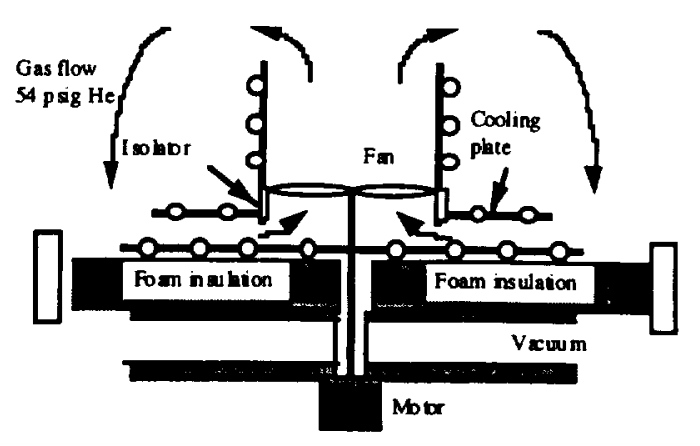

b. Cross-sectional view of the fan heat exchanger.

Figure 11. Details of the cryogenic cooling system

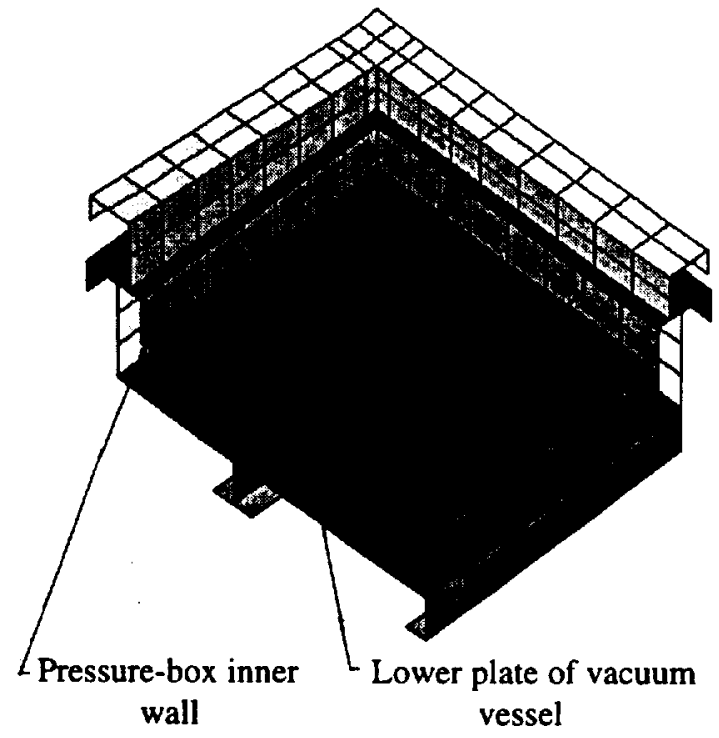

a. Finite element model.

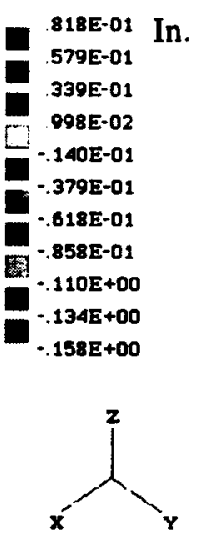

b. Deflection contours.

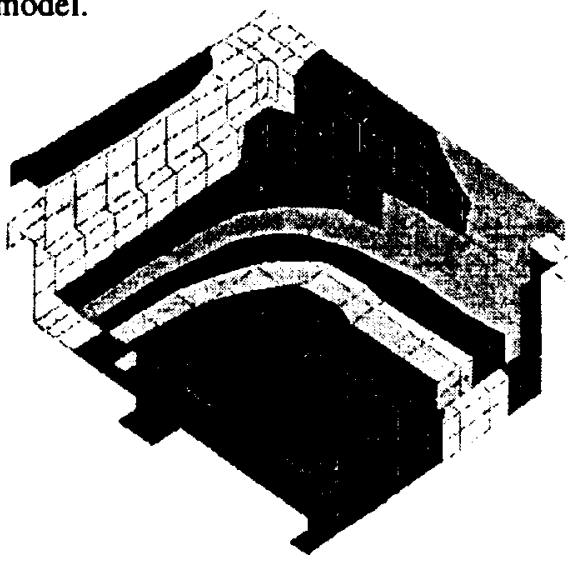

Figure 12. Structural response results for the pressure box. 


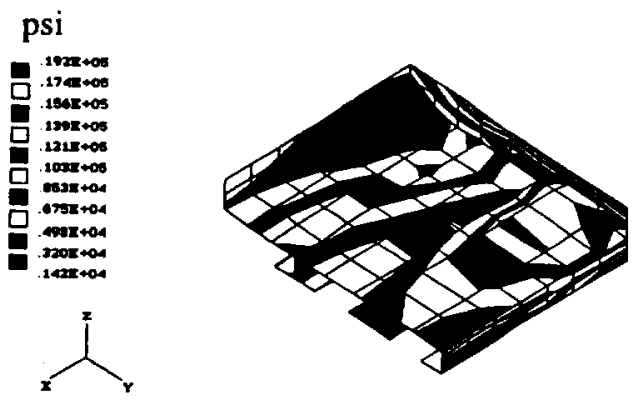

a. Pressure box inner walls.

psi

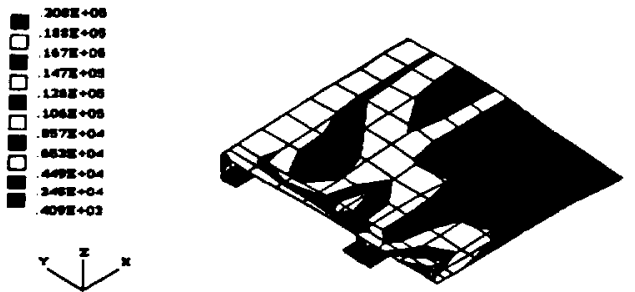

c. Boundary condition 3 .

Figure 14. Thermal gradients for the test panel assembly for different thermal boundary conditions.

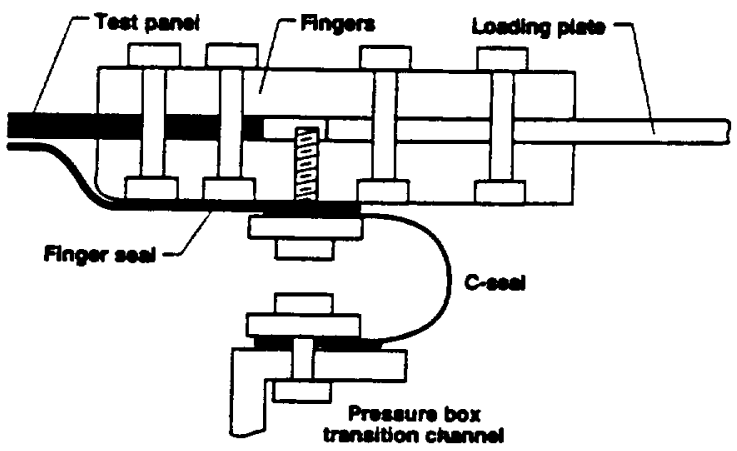

Figure 15. Seal arrangement for the test panel.

a. Boundary condition 1 .

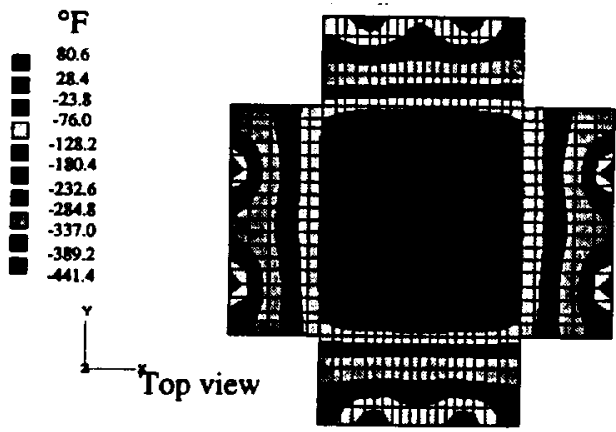

b. Boundary condition 2 .

Figure 14. Continued.

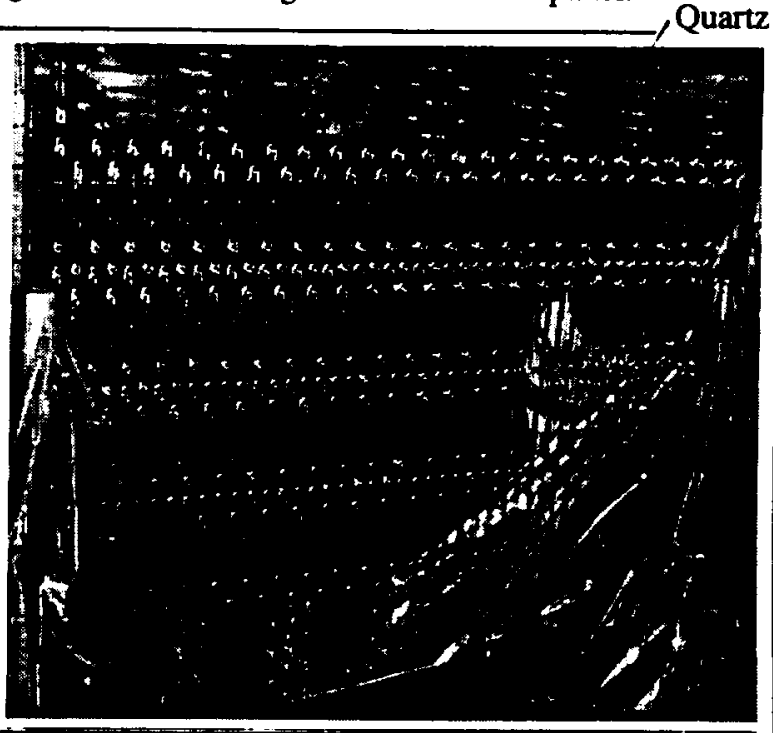

Figure 16. Finished heater with electrical wiring. 


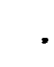

